\title{
The prevalence of metabolic syndrome and metabolically healthy obesity in Europe: a collaborative analysis of ten large cohort studies
}

Jana V van Vliet-Ostaptchouk ${ }^{1 \dagger}$, Marja-Liisa Nuotio ${ }^{2,3 \dagger}$, Sandra N Slagter ${ }^{1 \dagger}$, Dany Doiron ${ }^{4 \dagger}$, Krista Fischer $^{5}$, Luisa Foco ${ }^{6}$, Amadou Gaye ${ }^{7}$, Martin Gögele ${ }^{6}$, Margit Heier ${ }^{8}$, Tero Hiekkalinna ${ }^{2,3}$, Anni Joensuu ${ }^{2,3}$, Christopher Newby ${ }^{7}$, Chao Pang ${ }^{9,10}$, Eemil Partinen ${ }^{5}$, Eva Reischl ${ }^{11}$, Christine Schwienbacher ${ }^{6}$, Mari-Liis Tammesoo ${ }^{5}$, Morris A Swertz ${ }^{10}$, Paul Burton ${ }^{7}$, Vincent Ferretti ${ }^{12}$, Isabel Fortier ${ }^{4}$, Lisette Giepmans ${ }^{9}$, Jennifer R Harris ${ }^{13}$, Hans L Hillege ${ }^{9,14}$, Jostein Holmen ${ }^{15}$, Antti Jula ${ }^{16}$, Jenny E Kootstra-Ros ${ }^{17}$, Kirsti Kvaløy ${ }^{15}$, Turid Lingaas Holmen ${ }^{15}$, Satu Männistö ${ }^{18}$, Andres Metspalu ${ }^{5}$, Kristian Midthjell ${ }^{15}$, Madeleine J Murtagh ${ }^{7}$, Annette Peters ${ }^{8,11}$, Peter P Pramstaller ${ }^{6,19,20}$, Timo Saaristo ${ }^{21}$, Veikko Salomaa ${ }^{16}$, Ronald P Stolk ${ }^{9,22}$, Matti Uusitupa ${ }^{23}$, Pim van der Harst ${ }^{14}$, Melanie M van der Klauw ${ }^{1,22}$, Melanie Waldenberger ${ }^{11}$, Markus Perola ${ }^{2,3,5 \dagger}$ and Bruce HR Wolffenbuttel ${ }^{1,22^{*}+}$

\begin{abstract}
Background: Not all obese subjects have an adverse metabolic profile predisposing them to developing type 2 diabetes or cardiovascular disease. The BioSHaRE-EU Healthy Obese Project aims to gain insights into the consequences of (healthy) obesity using data on risk factors and phenotypes across several large-scale cohort studies. Aim of this study was to describe the prevalence of obesity, metabolic syndrome (MetS) and metabolically healthy obesity $(\mathrm{MHO})$ in ten participating studies.

Methods: Ten different cohorts in seven countries were combined, using data transformed into a harmonized format. All participants were of European origin, with age 18-80 years. They had participated in a clinical examination for anthropometric and blood pressure measurements. Blood samples had been drawn for analysis of lipids and glucose. Presence of MetS was assessed in those with obesity (BMI $\geq 30 \mathrm{~kg} / \mathrm{m}^{2}$ ) based on the 2001 NCEP ATP III criteria, as well as an adapted set of less strict criteria. MHO was defined as obesity, having none of the MetS components, and no previous diagnosis of cardiovascular disease.

Results: Data for 163,517 individuals were available; 17\% were obese (11,465 men and 16,612 women). The prevalence of obesity varied from $11.6 \%$ in the Italian CHRIS cohort to $26.3 \%$ in the German KORA cohort. The age-standardized percentage of obese subjects with MetS ranged in women from 24\% in CHRIS to 65\% in the Finnish Health2000 cohort, and in men from $43 \%$ in CHRIS to $78 \%$ in the Finnish DILGOM cohort, with elevated blood pressure the most frequently occurring factor contributing to the prevalence of the metabolic syndrome. The age-standardized prevalence of MHO varied in women from $7 \%$ in Health 2000 to $28 \%$ in NCDS, and in men from $2 \%$ in DILGOM to $19 \%$ in CHRIS. MHO was more prevalent in women than in men, and decreased with age in both sexes.

(Continued on next page)
\end{abstract}

\footnotetext{
* Correspondence: bwo@umcg.nl

${ }^{\dagger}$ Equal contributors

${ }^{1}$ Department of Endocrinology, University of Groningen, University Medical Center Groningen, HPC AA31, P.O. Box 30001, Groningen RB 9700, The Netherlands

${ }^{22}$ University of Groningen, University Medical Center Groningen, LifeLines

Cohort Study, Groningen, The Netherlands

Full list of author information is available at the end of the article
} 
(Continued from previous page)

Conclusions: Through a rigorous harmonization process, the BioSHaRE-EU consortium was able to compare key characteristics defining the metabolically healthy obese phenotype across ten cohort studies. There is considerable variability in the prevalence of healthy obesity across the different European populations studied, even when unified criteria were used to classify this phenotype.

Keywords: Harmonization, Obesity, Metabolic syndrome, Cardiovascular disease, Metabolically healthy

\section{Background}

The current obesity epidemic is one of the greatest public health concerns of our century [1]. In Europe, obesity has reached epidemic proportions [2]. A study assessing data collected between 1997 and 2003 reported that the prevalence of obesity, defined as body mass index (BMI) $\geq$ $30 \mathrm{~kg} / \mathrm{m}^{2}$, varied between $6 \%$ and $20 \%$, with higher prevalence in Central and Eastern European countries and lower values in France, Italy, and some Scandinavian countries [3]. Among U.S. adults, obesity $(\mathrm{BMI} \geq 30)$ prevalence has increased from $15 \%$ in the early 1970 s to the most recent estimate of $34 \%$ in 2009-2010 [4,5]. Similar patterns are seen in other countries and were shown to be comparable across different age, ethnic, educational and income groups [6]. If the observed trends of increasing prevalence of obesity persist, by 2030 the absolute number of obese individuals could rise to a total of 1.12 billion, accounting for $20 \%$ of the world's adult population [7].

Obesity is a major contributor to the global burden of chronic diseases and disabilities [1]. Increased adiposity is a key risk factor for type 2 diabetes, dyslipidaemia and cardiovascular disease, and is associated with many other conditions, including osteoarthritis, certain types of cancer, mental health, and increased mortality [8-13]. However, recent evidence indicates that obesity does not always lead to adverse metabolic effects such as impaired glucose tolerance, insulin resistance, dyslipidaemia and hypertension [14], a cluster of the obesity-driven alterations also known as the metabolic syndrome (MetS) [15,16]. A subgroup of approximately $10-30 \%$ of obese individuals is metabolically healthy despite having excessive accumulation of body fat [17-22]. This phenomenon is referred to in the current literature as metabolically healthy obesity (MHO) [23]. However, to date, little is known about the factors that delay onset of or protect obese individuals from developing metabolic disturbances [24].

Accumulating evidence indicates that the prevalence of $\mathrm{MHO}$ varies considerably based on the set of criteria used for its classification as well as on the cut-off values for each parameter included $[19,24,25]$. In addition, other factors such as lifestyle, ethnicity, sex, or age can largely influence the prevalence of MHO [19]. Recent observational studies show that the MHO phenotype is associated with lower risk of CVD [26] and mortality, especially in those physically active [27], although not all studies could confirm these findings [28]. This highlights the importance of investigating $\mathrm{MHO}$ using harmonized classification criteria and studying the extent to which $\mathrm{MHO}$ is associated with the risk for chronic diseases.

The BioSHaRE-EU Project is an international collaborative project between European and Canadian Institutes and European cohort studies. It aims to harmonize data from clinical examinations and analytical results from biospecimens, as well as measures of life style, social circumstances and environmental exposures. Computing infrastructure is developed enabling the effective pooling of data and research into critical sub-components of the phenotypes associated with common complex diseases (www.bioshare.eu) [29-31]. The Healthy Obese Project (HOP) is the first scientific project in BioSHaRE to use these tools in order to gain insights into the characterization, the determinants and consequences of (healthy) obesity. We report the results of the first phase of the HOP project, in which we jointly analysed data from 163,517 individuals in ten population-based cohort studies across Europe. The objectives were to assess the potential for harmonization and collaboration, and to evaluate the prevalence of MetS in obese participants using different classification criteria and by characterizing the clinical and metabolic factors associated with $\mathrm{MHO}$.

\section{Methods}

\section{Study participants}

This study included participants from ten population-based cohort studies in seven European countries as listed below. Data from 163,517 individuals were available from the following cohort studies: Estonia: the population-based biobank of the Estonian Genome Project of University of Tartu (EGCUT) $(\mathrm{n}=8,930)$ [32]; Finland: FINRISK2007 (DILGOM) $(n=3,685)$ [33] and Health2000 (H2000) $(n=6,022)$ [34]; Germany: the Cooperative Health Research in the Region of Augsburg (KORA) study ( $n=2,987)$ [35], Italy: Collaborative Health Research in South Tyrol Study (CHRIS) $(n=1,117)$ and the MICROS study $(n=1,060)$ [36]; the Netherlands: LifeLines $(n=63,995)$ [37], and the Prevention of REnal and Vascular ENd stage Disease study (PREVEND) $(\mathrm{n}=7,216)$ [38]; Norway: the Nord-Trøndelag health study (HUNT2 survey) $(\mathrm{n}=61,199)$ [39]; and United 
Kingdom: the National Child Development Study birth cohort (NCDS), also known as the 1958 birth cohort ( $\mathrm{n}=7,306)$ [40]. A brief description of all participating studies is given in the Additional file 1: Study descriptions and methodologies.

All study participants were of European origin, aged between 18 and 80 years, and had participated in a clinical examination for anthropometric and blood pressure measurements. Blood samples were taken for analysis of lipids and glucose (Additional file 1: Study descriptions and methodologies). Participants were only included if all data on clinical and metabolic measurements needed to define the status of MetS and obesity were available,. All cohorts had gained approval through their local research ethics committees or institutional review board for secondary usage of data. Participants gave their written informed consent to their study of origin. The current study protocol also gained approval under the data access and ethics governance requirements of the study of origin. The data on the outcomes measured in this study have not been published before by the individual cohorts.

\section{Data harmonization process}

Characteristics describing each cohort study (e.g. design, sample size) are catalogued in a systematic way on the BioSHaRE website (www.bioshare.eu). BioSHaRE investigators met at a workshop in order to define the set of variables to be generated from the harmonization process. These 'target' variables determine the data information content that is required from each study to generate compatible (i.e. harmonized) variables. By evaluating study-specific questionnaires, standard operating procedures and data dictionaries, used by the participating cohort studies, the potential for each cohort study to generate the target variables was determined. Then researchers working with the data transformed their data locally into a common harmonized format. Parts of this process have been published recently [31], and details related to pairing decisions taken and processing algorithms are available online (https://www.bioshare.eu/ content/healthy-obese-project-dataschema).

\section{Classification of obesity, metabolic syndrome and the MHO phenotype}

The criteria applied for measures of weight and height required that each cohort study measured participants when dressed in lightweight clothing and no shoes. Body mass index (BMI) was calculated as weight in kilograms divided by height in meters squared. Obesity was defined according to the current World Health Organization (WHO) classification as having a BMI $\geq 30 \mathrm{~kg} / \mathrm{m}^{2}$ [41].

Four clinical measures were used to define the MetS phenotype in the obese subjects based on the original
NCEP ATP III definition [42]: 1) elevated blood pressure, defined as systolic blood pressure $(\mathrm{SBP}) \geq 130 \mathrm{mmHg}$ or diastolic blood pressure (DBP) $\geq 85 \mathrm{mmHg}$, or antihypertensive drug treatment; 2) elevated fasting blood glucose level $\geq 6.1 \mathrm{mmol} / \mathrm{l}$ or use of blood glucose lowering agents or history/diagnosis of type 2 diabetes; 3 ) decreased HDLcholesterol level $(<1.03 \mathrm{mmol} / \mathrm{l}$ in men or $<1.30 \mathrm{mmol} / \mathrm{l}$ in women) or drug treatment aimed to increase HDLcholesterol; and 4) hypertriglyceridaemia (triglyceride level $\geq 1.70 \mathrm{mmol} / \mathrm{l}$ ) or drug treatment for elevated triglycerides (Table 1). Data on waist circumference was not available in all cohorts. However, > 95\% of LifeLines participants with obesity had increased waist circumference according to the NCEP ATP III definition [42], and we therefore considered the presence of $\geq 2$ of the four clinical measures as diagnostic for MetS [15]. In addition, we also applied a set of less strict criteria in which the cut-off levels for elevated systolic and diastolic blood pressure were set at $\geq 140 \mathrm{mmHg}$ and $\geq 90 \mathrm{mmHg}$, respectively, and the cut-off level for elevated fasting blood glucose was set at $7.0 \mathrm{mmol} / \mathrm{l}$. As the components of MetS can be influenced by smoking, we recorded whether the participants were current smokers.

The methodology for measurement of the laboratory variables in the various studies is described in the Additional file 1 . As not all participating cohorts had performed measurement of triglycerides in fasting serum samples, we corrected, as part of the harmonization process, non-fasting triglycerides values based on the findings of a recent report on the associations between fasting time and serum triglycerides levels (i.e. the threshold of $2.1 \mathrm{mmol} / \mathrm{l}$ was used) [43]. For the same reason, we used a different cutoff value for non-fasting blood glucose (i.e. thresholds of $7.0 \mathrm{mmol} / \mathrm{l}$ and $7.8 \mathrm{mmol} / \mathrm{l}$ for 'strict' and 'less strict' criteria were used, respectively (Table 1$)$ ). In the NCDS study, fasting blood glucose was calculated from HbA1c based on a regression formula obtained in the LifeLines Cohort Study (see Additional file 1).

We collected and analysed three types of information: (1) the presence of individual components of MetS in obese participants in each cohort study; (2) the number and percentage of MetS criteria fulfilled in obese participants in each cohort; and (3) the number and percentage of subjects fulfilling the criteria for being metabolically healthy obese in different age groups. MHO was established when subjects with obesity had none of the MetS components, and had no previous diagnosis of cardiovascular disease. As there were age differences between the cohorts, we performed age standardization against the European population, as defined by the EU-27 Member States population on January 1, 2010 (http://epp.eurostat. ec.europa.eu/portal/page/portal/statistics/search_database, accessed October 17, 2013). Prevalence was calculated for men and women separately based on 10-year age groups. 


\begin{tabular}{|c|c|c|}
\hline & Strict criteria & Less strict criteria \\
\hline Blood pressure & $\begin{array}{l}\mathrm{SBP} \geq 130 \mathrm{mmHg} \text { or } \mathrm{DBP} \geq 85 \mathrm{mmHg} \text { or } \\
\text { use of antihypertensive medication }\end{array}$ & $\begin{array}{l}\mathrm{SBP} \geq 140 \mathrm{mmHg} \text { or } \mathrm{DBP} \geq 90 \mathrm{mmHg} \\
\text { or use of antihypertensive medication }\end{array}$ \\
\hline Elevated blood glucose & $\begin{array}{l}\text { fasting blood glucose } \geq 6.1 \mathrm{mmol} / \mathrm{l} \text { or non-fasting } \\
\text { blood glucose } \geq 7.0 \mathrm{mmol} / \mathrm{l} \text { or use of blood glucose } \\
\text { lowering medication or diagnosis of type } 2 \text { diabetes }\end{array}$ & $\begin{array}{l}\text { fasting blood glucose } \geq 7.0 \mathrm{mmol} / \mathrm{l} \text { or non-fasting } \\
\text { blood glucose } \geq 7.8 \mathrm{mmol} / \mathrm{l} \text { or use of blood glucose } \\
\text { lowering medication or diagnosis of type } 2 \text { diabetes }\end{array}$ \\
\hline Decreased HDL-cholesterol & $\begin{array}{l}<1.03 \mathrm{mmol} / \mathrm{l} \text { in men or }<1.30 \mathrm{mmol} / \mathrm{l} \text { in } \\
\text { women or medical treatment for low HDL }\end{array}$ & $\begin{array}{l}<1.03 \mathrm{mmol} / \mathrm{l} \text { in men or }<1.30 \mathrm{mmol} / \mathrm{l} \\
\text { in women or medical treatment for low HDL }\end{array}$ \\
\hline Elevated triglycerides* & $\geq 1.70 \mathrm{mmol} / \mathrm{l}$ or medication for elevated triglycerides & $\begin{array}{l}\geq 1.70 \mathrm{mmol} / \mathrm{l} \text { or medication } \\
\text { for elevated triglycerides }\end{array}$ \\
\hline Diagnosis for CVD & Yes & Yes \\
\hline
\end{tabular}

Abbreviations: CVD cardiovascular disease, DBP diastolic blood pressure, SBP systolic blood pressure.

The presence of $\geq 2$ abnormal clinical measures (blood pressure, blood glucose, HDL-cholesterol, triglycerides) according to the strict criteria was considered diagnostic for MetS.

Metabolically healthy obesity is defined as having $\mathrm{BMI} \geq 30$, none of the following criteria of the metabolic syndrome [15,42], and no cardiovascular disease. *In case of non-fasting measurements, the cut-off value was set at $2.10 \mathrm{mmol} / \mathrm{l}$.

The definition of prevalent cardiovascular disease varied slightly between cohorts (Additional file 1: The definition of cardiovascular disease), but in the majority of cohort studies, it was based on self-reported history of acute myocardial infarction, stroke, angina pectoris or cardiovascular intervention (CABG or PTCA).

\section{Statistical analyses}

Results are presented as means \pm standard deviation, or number and percentage. Frequency of individual components of MetS were calculated, both for the whole population of obese individuals and for specific age categories. If needed, data are given for men and women separately. As this is a descriptive observational study, no formal statistical testing was performed.

\section{Results}

Overall, data for 163,517 individuals were available for the analysis, of whom 28,077 (17.2\%) were obese $(11,465$ (15.8\%) men and 16,612 (18.3\%) women). Table 2 summarizes the clinical characteristics of obese participants from each cohort study. Mean age of the obese participants varied from 44.0 to 59.6 years. In all cohorts, the frequency of obesity was greater among women than among men (only statistically significant $(\mathrm{P}<0.05)$ for Health2000, LifeLines, Prevend and HUNT2), while it was greater among men in the NCDS cohort $(\mathrm{P}=0.033)$. The highest prevalence of obesity was found in Germany (26.3\%, mean age of the participants 59.6 years), Finland (DILGOM cohort, 25.7\%, 57.3 years), Estonia (23\%, 52.6 years), and the United Kingdom (22.9\%, 44.0 years), while the lowest prevalence of obesity was observed in the Italian studies CHRIS (11.6\%, 53.6 years) and MICROS (14.8\%, 54.9 years) (Figure 1). The percentage of individuals currently smoking varied between 15 and 31\% (Table 2).
The observed prevalence of MetS was mainly driven by the presence of elevated blood pressure with a range from $60 \%$ to $85 \%$ of individuals fulfilling the criterion for high BP (Table 3, Figure 2). In contrast, elevated blood glucose contributed least to MetS, although we did observe considerable diversity between the cohorts. The percentage of obese individuals with elevated blood glucose varied from $7 \%$ in the UK NCDS cohort to $52 \%$ in the Finnish DILGOM cohort. A similar difference was observed in the percentage of the obese individuals with decreased HDL-cholesterol level: the lowest prevalence was observed in the Italian studies $(9 \%$ and $13 \%$ in the MICROS and CHRIS cohorts, respectively), while the highest prevalence was detected in the Dutch PREVEND cohort (57\%). The percentage of the individuals with elevated triglyceride levels ranged between $31 \%$ in the Dutch LifeLines study and 55\% in the UK NCDS participants. As a result, the age-standardized percentage of men with MetS according to the classic 2001 NCEP ATP III criteria ranged from $42.7 \%$ in the Italian CHRIS cohort to $78.2 \%$ in the Finnish DILGOM cohort, and for women from $24 \%$ in CHRIS to $64.8 \%$ in the Finnish Health2000 cohort (Figure 3A,B).

As expected, when less strict MetS criteria were used, the percentage of obese individuals with elevated blood pressure or blood glucose was lower (Table 3). This also resulted in a lower number of subjects with MetS (Table 4A,B).

Across all ten cohorts, a total of 3,387 obese participants (12\%) did not have any metabolic abnormalities according to the strict definition of MetS, as well as no previous diagnosis of cardiovascular disease, as defined by the MHO phenotype. After age standardization, the highest prevalence of $\mathrm{MHO}$ in men was found in the Italian CHRIS study (19\%) and in the German KORA study (13.5\%), and in women in UK NCDS (28.4\%), Dutch LifeLines (23.1\%), KORA (21.8\%) and CHRIS 
Table 2 Characteristics of the obese (BMI $\geq 30$ ) participants

\begin{tabular}{|c|c|c|c|c|c|c|c|c|c|c|}
\hline \multirow[t]{2}{*}{ Country \& study } & \multirow{2}{*}{$\begin{array}{l}\text { Estonia } \\
\text { EGCUT }\end{array}$} & \multicolumn{2}{|c|}{ Finland } & \multirow{2}{*}{$\begin{array}{c}\text { Germany } \\
\text { KORA }\end{array}$} & \multicolumn{2}{|c|}{ Italy } & \multicolumn{2}{|c|}{ The Netherlands } & \multirow{2}{*}{$\begin{array}{l}\text { Norway } \\
\text { HUNT2 }\end{array}$} & \multirow{2}{*}{$\begin{array}{c}\text { UK } \\
\text { NCDS }\end{array}$} \\
\hline & & DILGOM & Health2000 & & CHRIS & MICROS & LifeLines & PREVEND & & \\
\hline Total number of participants ( $\mathrm{N}$ ) & 8,930 & 3,685 & 6,022 & 2,987 & 1,117 & 1,060 & 63,995 & 7,216 & 61,199 & 7,306 \\
\hline Number with $\mathrm{BMI} \geq 30$ (\%) & $2,053(23.0)$ & $946(25.7)$ & $1,342(22.3)$ & $786(26.3)$ & $130(11.6)$ & $157(14.8)$ & $9,934(15.5)$ & $1,137(15.8)$ & $9,922(16.2)$ & $1,670(22.9)$ \\
\hline Gender (M (\%)/F) & $698(34.0) / 1,355$ & $399(42.2) / 547$ & $573(42.7) / 769$ & $373(47.5) / 413$ & $60(46.2) / 70$ & $57(36.3) / 100$ & $3,813(38.4) / 6,121$ & $514(45.2) / 623$ & $4,104(41.4) / 5,818$ & $874(52.3) / 796$ \\
\hline Age (yrs) & $52.6 \pm 14.1$ & $57.3 \pm 11.6$ & $54.5 \pm 12.8$ & $59.6 \pm 12.0$ & $53.6 \pm 12.9$ & $54.9 \pm 15.2$ & $47.4 \pm 11.7$ & $53.5 \pm 11.7$ & $53.5 \pm 15.4$ & $44.0 \pm 0$ \\
\hline $\mathrm{BMI}\left(\mathrm{kg} / \mathrm{m}^{2}\right)$ & $34.4 \pm 4.1$ & $34.2 \pm 4.1$ & $33.6 \pm 3.4$ & $33.8 \pm 3.7$ & $33.1 \pm 3.4$ & $33.6 \pm 4.5$ & $33.6 \pm 3.6$ & $33.2 \pm 3.3$ & $33.2 \pm 3.1$ & $33.9 \pm 3.8$ \\
\hline Waist circumference (cm) & $107 \pm 12$ & $110 \pm 11$ & $108 \pm 10$ & $109 \pm 11$ & NA & NA & $108 \pm 10$ & $105 \pm 11$ & $101 \pm 10$ & $106 \pm 10$ \\
\hline HDL cholesterol (mmol/l) & $1.52 \pm 0.33$ & $1.30 \pm 0.33$ & $1.17 \pm 0.32$ & $1.31 \pm 0.31$ & $1.54 \pm 0.45$ & $1.54 \pm 0.34$ & $1.28 \pm 0.33$ & $1.16 \pm 0.34$ & $1.24 \pm 0.35$ & $1.38 \pm 0.32$ \\
\hline Men & $1.35 \pm 0.28$ & $1.15 \pm 0.26$ & $1.05 \pm 0.27$ & $1.21 \pm 0.29$ & $1.31 \pm 0.32$ & $1.36 \pm 0.25$ & $1.13 \pm 0.26$ & $1.01 \pm 0.27$ & $1.10 \pm 0.29$ & $1.30 \pm 0.30$ \\
\hline Women & $1.60 \pm 0.32$ & $1.42 \pm 0.33$ & $1.26 \pm 0.32$ & $1.40 \pm 0.30$ & $1.74 \pm 0.45$ & $1.65 \pm 0.34$ & $1.38 \pm 0.33$ & $1.29 \pm 0.33$ & $1.35 \pm 0.36$ & $1.47 \pm 0.31$ \\
\hline Triglycerides (mmol/l) & $2.10 \pm 1.16$ & $1.82 \pm 1.01$ & $2.02 \pm 1.22$ & $1.77 \pm 1.09$ & $1.53 \pm 0.99$ & $1.87 \pm 1.27$ & $1.54 \pm 1.02$ & $1.88 \pm 1.33$ & $2.35 \pm 1.39$ & $2.17 \pm 1.63$ \\
\hline Blood glucose $(\mathrm{mmol} / \mathrm{l})$ & $4.8 \pm 1.8$ & $6.4 \pm 1.3$ & $5.9 \pm 1.7$ & $5.9 \pm 1.2$ & $5.6 \pm 0.9$ & $5.4 \pm 1.5$ & $5.4 \pm 1.3$ & $5.4 \pm 1.6$ & $5.9 \pm 2.0$ & $4.9 \pm 1.1$ \\
\hline Systolic blood pressure (mmHg) & $136 \pm 17$ & $140 \pm 19$ & $142 \pm 20$ & $128 \pm 18$ & $128 \pm 14$ & $143 \pm 22$ & $133 \pm 15$ & $139 \pm 20$ & $146 \pm 22$ & $132 \pm 16$ \\
\hline Diastolic blood pressure $(\mathrm{mmHg})$ & $84 \pm 11$ & $83 \pm 11$ & $87 \pm 10$ & $78 \pm 10$ & $83 \pm 8$ & $85 \pm 11$ & $77 \pm 9$ & $77 \pm 10$ & $85 \pm 13$ & $83 \pm 10$ \\
\hline Current smoking (\%) & 30.5 & 15.3 & 23.0 & 17.7 & 15.4 & 28.0 & 19.9 & 26.3 & 30.8 & 23.9 \\
\hline Number with MetS (M/F) & $410 / 606$ & $323 / 355$ & $425 / 515$ & $229 / 216$ & $26 / 26$ & $34 / 33$ & $2,208 / 2,262$ & $346 / 335$ & $2,792 / 3,114$ & $513 / 269$ \\
\hline Number with $\mathrm{MHO}(\mathrm{M} / \mathrm{F})$ & $34 / 166$ & $7 / 37$ & $19 / 43$ & $34 / 61$ & $11 / 12$ & $4 / 9$ & $359 / 1,433$ & $26 / 94$ & $180 / 553$ & $79 / 226$ \\
\hline
\end{tabular}




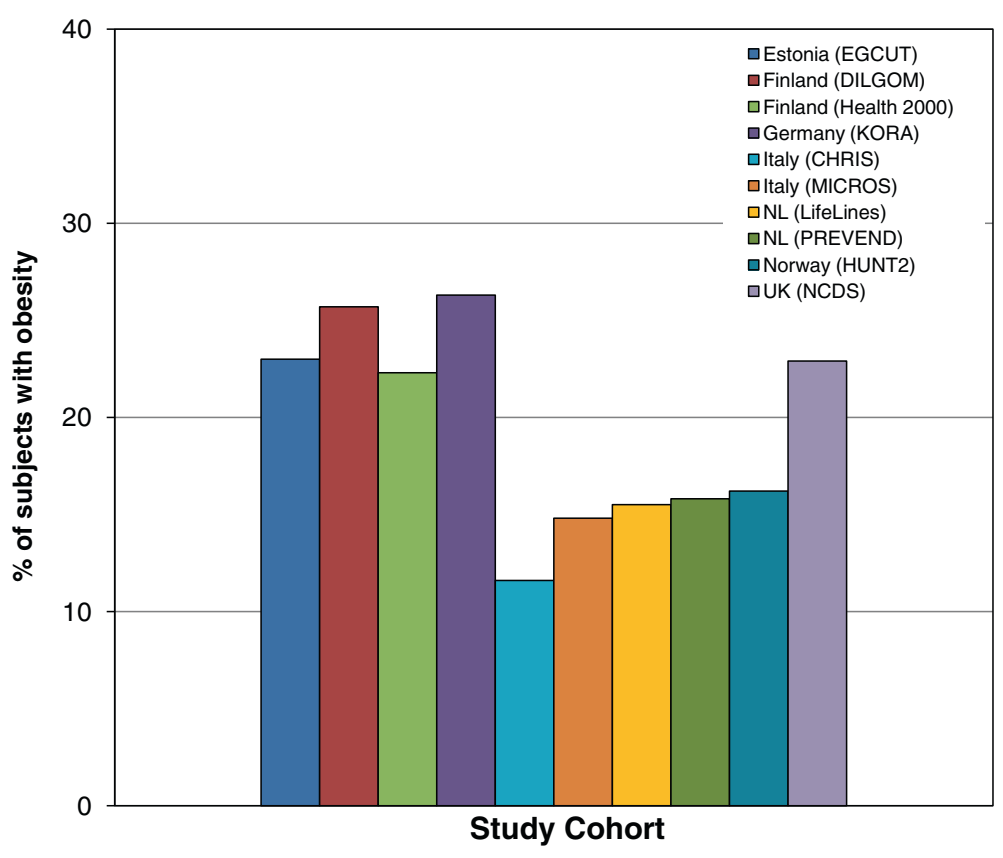

Figure 1 The prevalence of obesity in the participating cohorts given as a percentage of the total sample size of the cohort.

(21.1\%). The lowest prevalence was observed in the two Finnish cohorts $(2.3$ and $3.6 \%$ for men, 7.3 and $12.3 \%$ for women) and the Norwegian HUNT2 study $(5.9 \%$ in men, $14 \%$ in women) (Figure $3 \mathrm{~A}, \mathrm{~B}$ ).

The trend towards a higher percentage of $\mathrm{MHO}$ in women compared with men was evident in almost all studies. This sex difference was most apparent in the NCDS cohort, in which $28.4 \%$ of obese women were metabolically healthy in comparison with only $9 \%$ of obese men with the same phenotype (Figure 3 ). In contrast, the percentage of men and women with $\mathrm{MHO}$ was similar in the Italian CHRIS study (19\% versus $21.1 \%)$. These findings were also independent of the definition of $\mathrm{MHO}$, as we observed the same tendency with both strict and less strict criteria (data not shown).

Overall, we observed a decrease in the prevalence of $\mathrm{MHO}$ with increasing age, independent of sex and the MetS definition criteria used (Figure 4A,B). This pattern was seen in all cohorts except the Italian CHRIS study, in which the prevalence of $\mathrm{MHO}$ appeared to be relatively constant until the age of 60 . In all cohorts, a subset of the obese individuals remained metabolically healthy, even in the oldest age group ( $\geq 60$ years). The highest prevalence of $\mathrm{MHO}$ among those 60 years and older was observed in the Dutch LifeLines study (8\%).

Table 3 The frequency of individual components of the metabolic syndrome in obese (BMI $\geq 30)$ individuals

\begin{tabular}{|c|c|c|c|c|c|c|c|c|c|c|}
\hline & \multirow{2}{*}{$\begin{array}{l}\text { Estonia } \\
\text { EGCUT }\end{array}$} & \multicolumn{2}{|c|}{ Finland } & \multirow{2}{*}{$\begin{array}{c}\text { Germany } \\
\text { KORA }\end{array}$} & \multicolumn{2}{|c|}{ Italy } & \multicolumn{2}{|c|}{ The Netherlands } & \multirow{2}{*}{$\begin{array}{l}\text { Norway } \\
\text { HUNT2 }\end{array}$} & \multirow{2}{*}{$\begin{array}{c}\text { UK } \\
\text { NCDS }\end{array}$} \\
\hline & & DILGOM & Health2000 & & CHRIS & MICROS & LifeLines & PREVEND & & \\
\hline Total N & 2,053 & 946 & 1,342 & 786 & 130 & 157 & 9,934 & 1,137 & 9,922 & 1,669 \\
\hline \multicolumn{11}{|l|}{ Metabolic component } \\
\hline $\begin{array}{l}\text { Strict criterium for } \\
\text { high } \mathrm{BP}(\%)\end{array}$ & $1,637(79.7)$ & $801(84.7)$ & $1,104(82.3)$ & $573(72.9)$ & $83(63.9)$ & $123(78.3)$ & $6,407(64.5)$ & $825(72.6)$ & 7,991 (80.5) & 998 (59.8) \\
\hline $\begin{array}{l}\text { Strict criterium for } \\
\text { blood glucose }(\%)\end{array}$ & $482(23.4)$ & $493(52.1)$ & $329(24.5)$ & $251(31.9)$ & $27(20.8)$ & $25(15.9)$ & $1,524(15.3)$ & $161(14.2)$ & $1,377(13.9)$ & $114(6.8)$ \\
\hline $\begin{array}{l}\text { Criterium for HDL } \\
\text { cholesterol (\%) }\end{array}$ & $273(13.3)$ & $346(36.6)$ & $750(55.9)$ & $281(35.8)$ & $17(13.1)$ & $14(8.9)$ & $3,913(39.4)$ & $646(56.8)$ & $4,547(45.8)$ & $387(23.2)$ \\
\hline $\begin{array}{l}\text { Criterium for } \\
\text { triglycerides (\%) }\end{array}$ & $815(39.7)$ & $407(43.0)$ & $710(52.9)$ & $317(40.3)$ & $44(33.9)$ & $68(43.3)$ & $3,028(30.5)$ & 496 (43.6) & 4,693 (47.3) & 912 (54.6) \\
\hline $\begin{array}{l}\text { Less strict criterium } \\
\text { for high BP (\%) }\end{array}$ & $1,386(67.5)$ & $670(70.8)$ & $916(68.3)$ & $498(63.4)$ & $64(49.2)$ & $98(62.4)$ & $4,492(45.2)$ & $660(58.2)$ & $6,447(65.0)$ & 609 (36.5) \\
\hline $\begin{array}{l}\text { Less strict criterium } \\
\text { for blood glucose (\%) }\end{array}$ & $463(22.5)$ & 176 (18.6) & $148(11.0)$ & 135 (17.2) & $12(9.2)$ & $12(7.6)$ & $825(8.3)$ & $87(7.7)$ & $920(9.3)$ & $92(5.5)$ \\
\hline
\end{tabular}




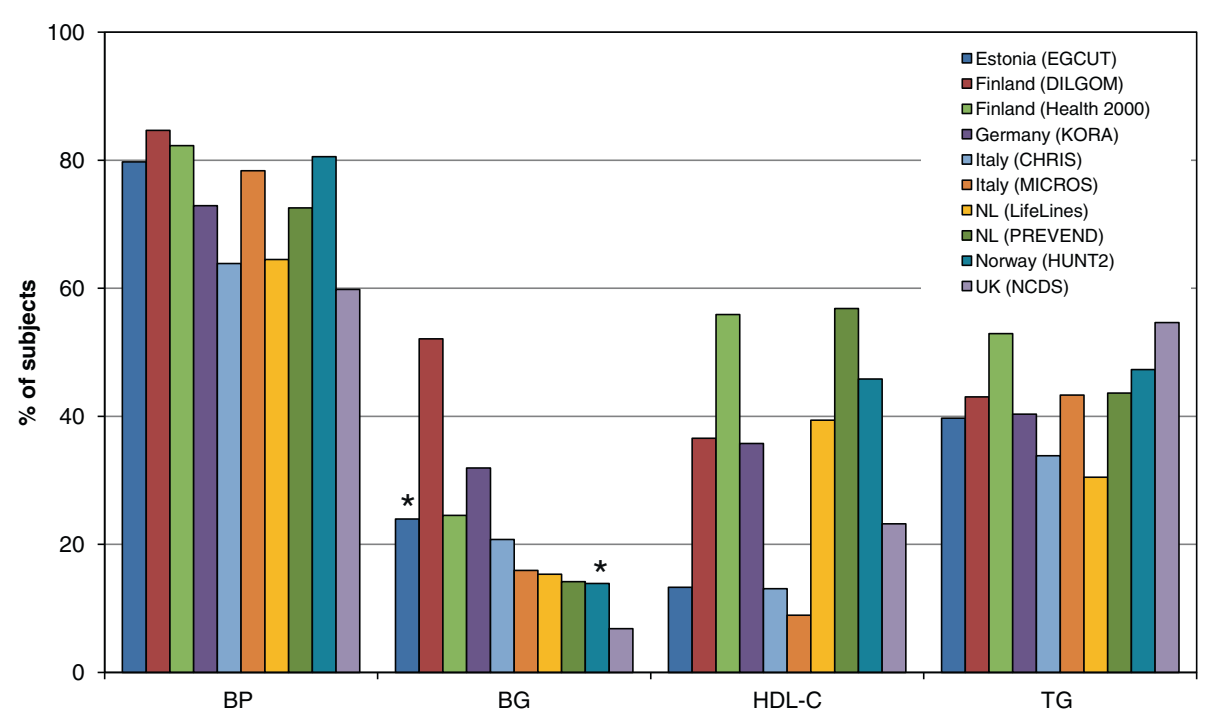

Figure 2 The frequency of individual components of the metabolic syndrome among obese subjects (BMI $\geq 30 \mathrm{~kg} / \mathrm{m}^{2}$ ). The presence of the metabolic syndrome mainly depends on the presence of a high blood pressure followed by the level of triglycerides and HDL cholesterol and - to a lesser extent - blood glucose levels. BP = blood pressure, BG = blood glucose, HDL-C = high density lipoprotein cholesterol, $\mathrm{TG}=$ triglycerides. ${ }^{*}$ Denotes non-fasting measurement of blood glucose.

\section{Discussion}

In this large-scale collaborative study, we evaluated the prevalence of metabolic syndrome and healthy obesity among obese individuals using the data of 163,517 people from ten European cohort studies from seven different countries. We found considerable variation in the prevalence of both phenotypes suggesting that the distribution of the MetS and MHO across the different populations in general is not equal. However, our analysis did reveal a consistently higher prevalence of the MHO phenotype in women compared to men. Furthermore, the percentage of obese subjects with a favourable risk profile decreases with increasing age in all cohorts.
With the exception of the Italian, Norwegian and UK cohorts, the prevalence of obesity was much higher in the European populations we studied than was reported in the most recent review addressing the distribution of obesity in Europe [2]. Such differences may be due to potential underestimation of the prevalence of obesity in the systematic review because of the inclusion of studies using self-reported BMI [2]. In our study, the data on BMI were obtained through direct measurements made by trained research nurses or study assistants which provides more accurate estimation of obesity prevalence in the participating cohorts. Another explanation for the discrepancy in the prevalence patterns may be related to the difference in
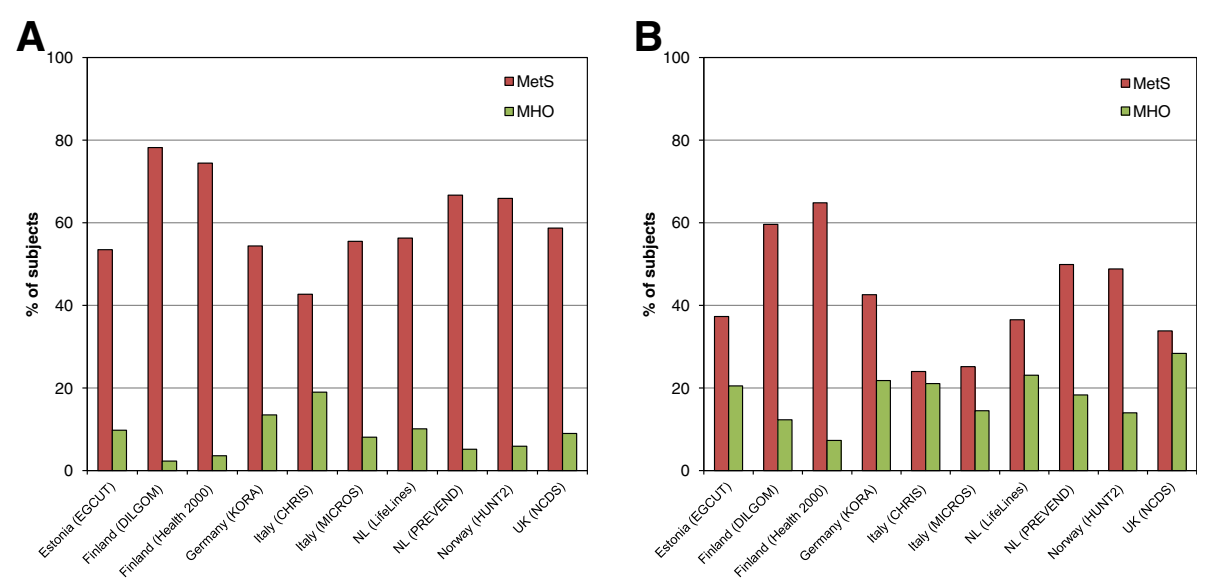

Figure 3 Age-standardized prevalence of metabolic syndrome (MetS) and metabolically healthy obesity (MHO) amongst obese $\left(B M I \geq 30 \mathrm{~kg} / \mathrm{m}^{2}\right)$ individuals in the participating cohorts, separately shown for men (panel A, left) and women (panel B, right). 
Table 4 Number of components of the metabolic syndrome (waist circumference not included) present among obese participants

\begin{tabular}{|c|c|c|c|c|c|c|c|c|c|c|}
\hline \multirow[t]{2}{*}{ A. Number of MetS component (strict criteria) } & \multirow{2}{*}{$\begin{array}{l}\text { Estonia } \\
\text { EGCUT }\end{array}$} & \multicolumn{2}{|c|}{ Finland } & \multirow{2}{*}{$\begin{array}{c}\text { Germany } \\
\text { KORA }\end{array}$} & \multicolumn{2}{|c|}{ Italy } & \multicolumn{2}{|c|}{ The Netherlands } & \multirow{2}{*}{$\begin{array}{l}\text { Norway } \\
\text { HUNT2 }\end{array}$} & \multirow{2}{*}{$\begin{array}{c}\text { UK } \\
\text { NCDS }\end{array}$} \\
\hline & & DILGOM & Health2000 & & CHRIS & MICROS & Lifelines & PREVEND & & \\
\hline Total N & 2,053 & 946 & 1,342 & 786 & 130 & 157 & 9,934 & 1,137 & 9,922 & 1,669 \\
\hline 0 criteria present (\%) & $242(11.8)$ & $46(4.9)$ & $76(5.7)$ & $98(12.5)$ & $38(29.2)$ & $18(11.5)$ & $1,808(18.2)$ & $120(10.6)$ & $755(7.6)$ & $305(18.3)$ \\
\hline 1 criterium present (\%) & $793(38.6)$ & $222(23.5)$ & $326(24.3)$ & $243(31.0)$ & $40(30.8)$ & $72(45.9)$ & $3,656(36.8)$ & $336(29.6)$ & $3,261(32.9)$ & $582(34.9)$ \\
\hline 2 criteria present (\%) & $689(33.6)$ & $309(32.7)$ & $400(29.8)$ & $227(28.9)$ & $31(23.9)$ & $45(28.7)$ & $2,604(26.2)$ & $323(28.4)$ & $2,916(29.4)$ & $565(33.9)$ \\
\hline 3 criteria present (\%) & $270(13.2)$ & $269(28.4)$ & $393(29.3)$ & $147(18.7)$ & $15(11.5)$ & $20(12.7)$ & $1,456(14.7)$ & $286(25.2)$ & $2,445(24.6)$ & $169(10.1)$ \\
\hline 4 criteria present (\%) & $59(2.9)$ & $100(10.6)$ & $147(11.0)$ & $71(9.0)$ & $6(4.6)$ & $2(1.3)$ & $410(4.1)$ & $72(6.3)$ & $545(5.5)$ & $48(2.9)$ \\
\hline \multirow[t]{2}{*}{ B. Number of MetS components (less strict criteria) } & Estonia & \multicolumn{2}{|c|}{ Finland } & Germany & \multicolumn{2}{|c|}{ Italy } & \multicolumn{2}{|c|}{ The Netherlands } & Norway & UK \\
\hline & EGCUT & DILGOM & Health2000 & KORA & CHRIS & MICROS & LifeLines & $\overline{\text { PREVEND }}$ & HUNT2 & NCDS \\
\hline Total N & 2,053 & 946 & 1,342 & 786 & 130 & 157 & 9,934 & 1,137 & 9,922 & 1,669 \\
\hline 0 criteria present (\%) & 381 (18.6) & $112(11.8)$ & $134(10.0)$ & $140(17.8)$ & $53(40.8)$ & $29(18.5)$ & $2,767(27.9)$ & $172(15.1)$ & $1,335(13.5)$ & $452(27.1)$ \\
\hline 1 criterium present (\%) & 778 (37.9) & $319(33.7)$ & $375(27.9)$ & $260(33.1)$ & $35(26.9)$ & $77(49.0)$ & $3,582(36.1)$ & $344(30.3)$ & 3,304 (33.3) & $613(36.7)$ \\
\hline 2 criteria present (\%) & $619(30.2)$ & $307(32.5)$ & $426(31.7)$ & $221(28.1)$ & $27(20.8)$ & $39(24.8)$ & $2,290(23.1)$ & $355(31.2)$ & $2,901(29.2)$ & $456(27.3)$ \\
\hline 3 criteria present (\%) & $227(11.1)$ & $166(17.6)$ & $331(24.7)$ & $131(16.7)$ & $12(9.2)$ & $11(7.0)$ & $1,084(10.9)$ & $229(20.1)$ & $2,027(20.4)$ & $117(7.0)$ \\
\hline 4 criteria present (\%) & $48(2.3)$ & $42(4.4)$ & $76(5.7)$ & $34(4.3)$ & $3(2.3)$ & $1(0.6)$ & $211(2.1)$ & $37(3.3)$ & 355 (3.6) & $31(1.9)$ \\
\hline
\end{tabular}



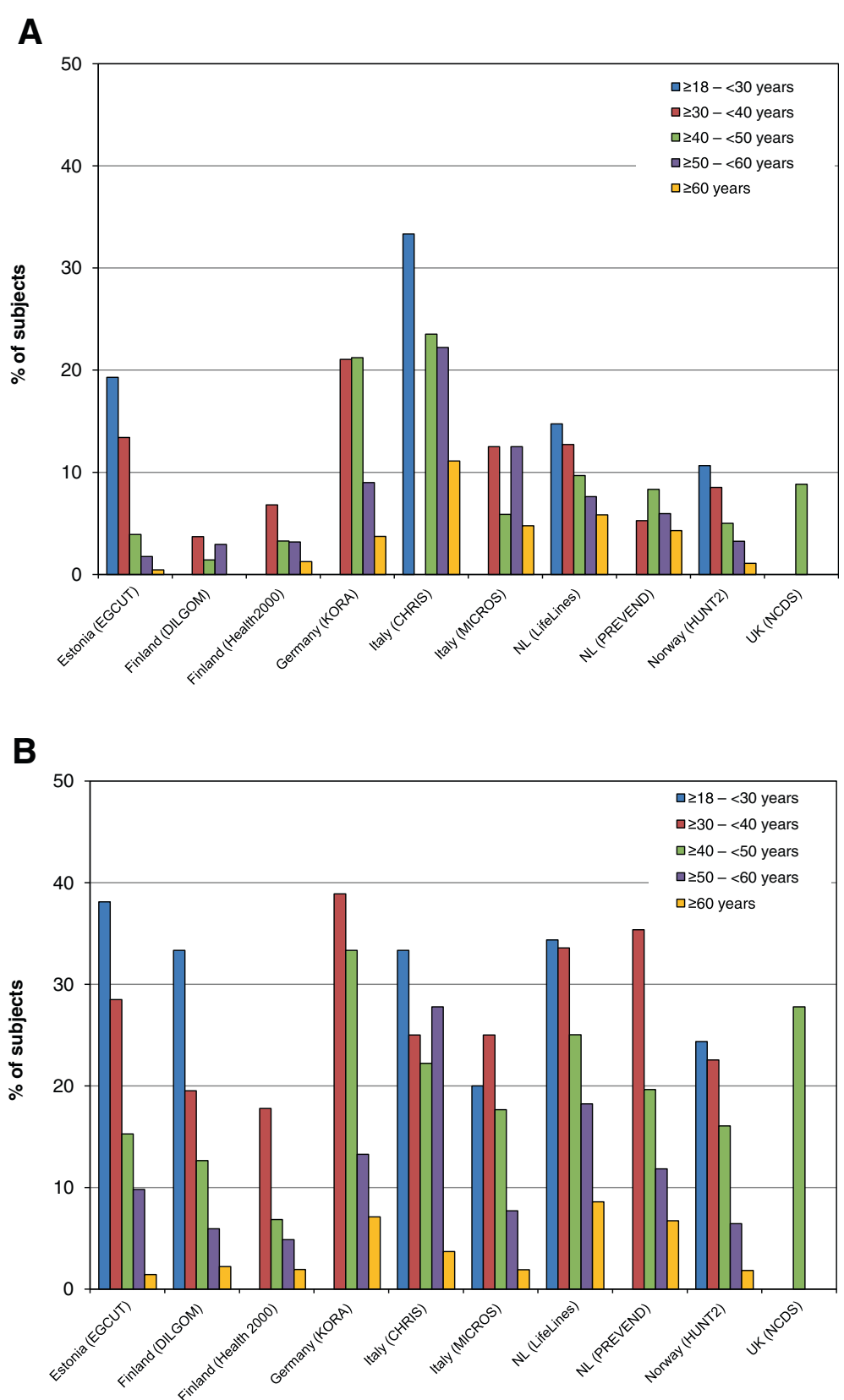

Figure 4 Percentage of subjects (panel A: men; panel B: women) meeting the criteria of being 'healthy obese'. The results are stratified for different age groups. In general, within each cohort the prevalence of healthy obesity decreases with increasing age. Note that more females are metabolically healthier than males.

the time period when the studies were conducted. While the surveys included in the systematic review were performed between the mid-1980s and 2003, most of the data in our study were collected after 2000, with the earliest data available from 1995 and the most recent data from 2012. The differences in estimations of the obesity prevalence can, therefore, present different phases of an increasing trend. Although our data are obtained from large population-based cohort studies or biobanks, we have to realize that our results cannot always be generalized to the overall prevalence in the specific countries, as some cohorts have only collected data from a specific region of that country (CHRIS/MICROS/HUNT2), or from a specific age group (NCDS). Despite the detected variation, the data confirm the observations that obesity in European countries continued to rise the last decade and has reached epidemic proportions [2]. However, recent publications suggest levelling off of the obesity epidemic [44-46], although in subjects 
with lower socioeconomic status a steady increase in prevalence still is observed [47].

The Finnish cohorts had the highest prevalence of MetS among obese subjects and the lowest percentage of MHO. In contrast, in the Italian MICROS and the Dutch LifeLines studies we observed a lower prevalence of MetS among obese subjects together with a higher percentage of MHO. Similar patterns in the occurrence of MetS in Europe have been reported previously [48]. MetS is a constellation of metabolic risk factors, associated with an increased risk for the development of atherosclerotic cardiovascular disease as well as type 2 diabetes mellitus $[15,16,49]$. MetS has been shown to be the major risk determinant of heart disease, also when a population generally has low levels of HDL- and LDL-cholesterol [50]. The most frequent MetS component present in obese individuals was elevated blood pressure. In the 10 studies, obesity coincided with hypertension in $60 \%$ to $85 \%$ cases. In contrast, we observed considerable variations in the prevalence of other components of MetS, especially blood glucose and HDLcholesterol. A blood pressure exceeding the strict criterion for a high blood pressure can be accounted as a main contributor promoting unhealthy obesity and metabolic syndrome in the Finnish cohorts in this study. Finnish tendency for elevated blood pressure has also been detected earlier, recently by The European Heart Network and The European Society of Cardiology [51].

Our study extends previous efforts to describe the phenomenon of healthy obesity and to estimate its prevalence in different countries in several important ways, including helping to disentangle whether differences in the prevalence of $\mathrm{MHO}$ are due to geographic variation or differences in measurements. Using a large amount of validated information, we applied a rigorous protocol to harmonize data from multiple populationbased European studies, and ensure a high level of homogeneity of the MetS definition used to calculate the MHO prevalence. Recently, the lack of a standard approach to use the same sets of criteria and cut-off values to define metabolic abnormalities has been highlighted as the major source of the high variability in the reported MHO prevalence $[19,24,25]$. Yet, our results also demonstrate a significant diversity in the prevalence of $\mathrm{MHO}$ across Europe using the harmonized criteria to define MetS. The highest percentage of $\mathrm{MHO}$ in men was found in CHRIS and KORA, and in women in NCDS, LifeLines, KORA and CHRIS, whereas the lowest prevalence was found in the Finnish cohorts and in HUNT2. In our study, we have used the established risk factors associated with the metabolic syndrome $[41,42]$ to identify the MHO phenotype. Our data on MetS components is consistent with the outcome of previously performed studies on the prevalence of the metabolic abnormalities in Europe [48,52]. As age and sex are important factors in the development of MetS, we have also evaluated the age- and sex-stratified prevalence of $\mathrm{MHO}$ per decade. Our results indicate a higher prevalence of the $\mathrm{MHO}$ phenotype in women than in men as well as an age-related decline in the percentage of obese subjects with a metabolically healthy phenotype $[19,24]$. Collectively, our findings raise additional questions about the underlying factors promoting the variation in the prevalence of $\mathrm{MHO}$ across different populations. Such variation in the distribution of metabolic phenotypes can be explained by several factors, including difference in age of the cohort participants, differences in environmental factors such as physical activity level, diet, smoking and alcohol use, and differences in the selection and inclusion of participants [52]. Also the psychosocial profile and genetic factors $[19,24]$ may play a role. While behavioral factors, i.e. higher levels of physical activity or moderate alcohol intake, have been shown to be associated with the $\mathrm{MHO}$ phenotype [18], there is no evidence yet whether genetic background and divergence between populations does contribute to the metabolically favorable profile in obesity [24].

Given the number of serious health problems associated with obesity including type 2 diabetes, cardiovascular disease, and an increased risk for various types of cancer, the investigation of the healthy obesity phenotype may provide novel insights into the pathophysiology of obesity-related co-morbidities and help to identify at-risk obese individuals. Furthermore, it may help in the development of better interventions for obese patients. There are strong indications that weight loss may not have a beneficial effect on certain metabolic risk factors in MHO individuals [20] and even result in a paradoxical response [53]. Therefore, the one-size-fits-all approach regarding the consequences of obesity should be revisited, and the prevailing concept in the health care system that obesity is always bad should be re-evaluated. Also, a proper classification of the at-risk and metabolically benign obese individuals should be taken into account in medical research to prevent any bias in the interpretation of the results.

The main strengths of this descriptive study are the large sample size and the application of harmonized criteria to evaluate the prevalence of MetS and the degree of the MHO across different European cohort studies. Through our harmonization process [31], we have shown the possibility for collaborative research based on a careful harmonization process across multiple participating cohort studies. Several important factors may have a bearing on the results. First, we used BMI to define the obesity status. Since BMI is a measure of general obesity and cannot distinguish between fat and lean mass, other measures such as waist circumference (WC) or waist-hip-ratio (WHR) might be better indicators of visceral fat accumulation. Although a few studies reported lower fat accumulation in $\mathrm{MHO}$ 
individuals compared to the obese with metabolic abnormalities $[17,24]$, no difference in the prevalence of $\mathrm{MHO}$ was found when WC was used instead of BMI to define the MHO phenotype in the NHANES cohort [18]. Second, although our harmonized measures captured the essential information content for the MHO phenotype, there were differences between studies in the way that specific variables such as blood pressure and serum lipid levels were measured. Also, our cut-off values for non-fasting measurements of, for example, blood glucose may underestimate the actual degree of the MHO present in the corresponding studies. Third, although many participating cohort studies included several thousands of participants, their health and lifestyle habits may not always be representative of the general population in this specific country because of bias in participation or differences in recruitment of participants. We also cannot exclude that a potential participation bias could affect the results [54]. As such, higher participation rates from either healthy or unhealthy individuals can influence the outcome, and it cannot be ruled out that the high percentage of $\mathrm{MHO}$ in the LifeLines Cohort Study may - at least in part - be explained by a preponderance of healthy individuals willing to participate.

An important factor to discuss is the time period in which the initial screening of each individual cohort was performed. Data in some cohorts were collected in the 1990s, while, for example, the participants in the Dutch LifeLines Cohort Study were recruited between 2007 and 2012, and in the Italian CHRIS study after August 2011. There have been several changes in environmental factors such as health behaviour and smoking pattern over time, which may have a bearing on the prevalence of MetS and on health in general. In many countries higher awareness of the importance of increased physical activity [55] or smoking cessation [56,57] have been recognized, although it appears that the current epidemic of obesity is still ongoing [2]. As an example, cessation of smoking is on one hand associated with weight gain [58], which may be perceived negatively by individuals [59], but it also results in improvement of the metabolic profile as smoking cessation is accompanied by an increase of HDL cholesterol and reduction of triglycerides [60]. It is important to note that the major objective of this descriptive study was to evaluate the phenomenon of healthy obesity among the participating European population-based studies. The BioSHaRE-HOP consortium is currently expanding its harmonization efforts, and assessing differences in lifestyle factors such as nutritional habits, physical activity, smoking and general awareness of health between the various participating countries in order to have a better estimate of the characterization and the determinants of (healthy) obesity.

\section{Conclusion}

In summary, we report the first scientific results of this collaborative project on the prevalence of healthy obesity within a FP7 funded consortium, BioSHaRE-EU. We have co-analysed data across the participating studies by applying careful harmonization algorithms. The present findings indicate considerable variation in the occurrence of $\mathrm{MHO}$ across the different European populations even when unified criteria or definitions were used to classify this phenotype. Further studies are needed to identify the underlying factors for these differences. This area of research will improve our understanding of obesity in general and possibly identify novel preventive measures for the consequences of obesity.

\section{Additional file}

Additional file 1: Study descriptions and methodologies. See enclosed file with supplementary information.

\section{Competing interests}

The authors declare that they have no competing interests.

\section{Authors' contributions}

MP, BHRW, RPS, PB, IF conceived the study. JVVVO, MLN, SNS, DD, MP and $\mathrm{BHRW}$ have been involved in integration of all analyses, data interpretation and drafting the manuscript. MLN, JVVVO, SNS, KF, LF, AJ, CN, CP, HLH, ER, KK coordinated and performed the harmonization and local analysis and interpretation of the data of all participating studies. AG, MG, MH, TH, EP, CS, MLT, MAS, PB, VF, IF, LG, JH, JEKR, TLH, SM, AM, KM, MJM, AP, PPP, TS, VS, RPS, MU, PvdH, MMvdK, MW, MP and BHRW were involved in local study design, collection of data, and/or coordination and execution of measurements and biochemical analyses. LG, JRH helped with the data interpretation and drafting the manuscript. All authors provided intellectual contributions to the manuscript and have read and approved the final version.

\section{Authors' information}

Jana V van Vliet-Ostaptchouk, Marja-Liisa Nuotio, Sandra N Slagter, Dany Doiron, equal contribution as first author; Markus Perola, Bruce HR Wolffenbuttel, equal contributors as last author.

\section{Acknowledgements}

This work was supported by funds from the European Union's Seventh Framework programme (FP7/2007-2013) through the BioSHaRE-EU (Biobank Standardisation and Harmonisation for Research Excellence in the European Union) project, grant agreement 261433.

BioSHaRE is engaged in a Bioresource research impact factor (BRIF) policy pilot study, details of which can be found at: https://www.bioshare.eu/content/ bioresource-impact-factor.

We wish to acknowledge the participating studies for providing the data and participating in the analyses and writing of the manuscript:

Estonian Genome Project of University of Tartu (EGCUT),

The National FINRISK Study (DILGOM, BRIF1640),

Health2000 (BRIF8901)

Cooperative Health Research in the Augsburg Region (Kooperative Gesundheitsforschung in der Region Augsburg, KORA, BRIF7781) Collaborative Health Research in South Tyrol Study (CHRIS, BRIF6107) Microisolates in South Tyrol Study (MICROS, BRIF2155) LifeLines Cohort Study (LifeLines, BRIF4568)

Prevention of REnal and Vascular ENd stage Disease (PREVEND, BRIF2709) The Nord-Trøndelag health study (HUNT2, BRIF2365)

1958 National Child Development Study (NCDS, BRIF4310) In addition, we would like to thank K.J. Jager (PhD, ERA-EDTA Registry, Academic Medical Center, Amsterdam, The Netherlands) and A. Kramer (PhD, 
ERA-EDTA Registry, Academic Medical Center, Amsterdam, The Netherlands) for providing statistical advice.

For acknowledgements per cohort, see the supplementary information.

\section{Role of the funding source}

The funders of the study did not participate in study design, data collection, data analysis, data interpretation, or writing of the report. Corresponding authors had full access to all the data in the study and had final responsibility for the decision to submit for publication.

\section{Author details}

'Department of Endocrinology, University of Groningen, University Medical Center Groningen, HPC AA31, P.O. Box 30001, Groningen RB 9700, The Netherlands. ${ }^{2}$ Institute for Molecular Medicine Finland (FIMM), University of Helsinki, Helsinki, Finland. ${ }^{3}$ Unit of Public Health Genomics, National Institute for Health and Welfare, Helsinki, Finland. ${ }^{4}$ Research Institute of the McGill University of Health Centre, Montreal, Canada. ${ }^{5}$ University of Tartu, Estonian Genome Center, Tartu, Estonia. ${ }^{6}$ Center for Biomedicine, European Academy of Bolzano/Bozen (EURAC), Bolzano, Italy. ${ }^{7}$ Data to Knowledge Research Group, School of Social and Community Medicine, University of Bristol, Bristol, UK. ${ }^{8}$ Institute of Epidemiology II, Helmholtz Zentrum München, German Research Center for Environmental Health, Neuherberg, Germany. ${ }^{9}$ Department of Epidemiology, University of Groningen, University Medical Center Groningen, Groningen, The Netherlands. ${ }^{10}$ Genomics Coordination Center, University of Groningen, Groningen Bioinformatics Center, and University Medical Center Groningen, Groningen, The Netherlands.

${ }^{11}$ Research Unit of Molecular Epidemiology, Helmholtz Zentrum München, German Research Center for Environmental Health, Neuherberg, Germany.

${ }^{12}$ Ontario Institute for Cancer Research, Toronto, ON, Canada. ${ }^{13}$ Department of Genes and Environment, Division of Epidemiology, The Norwegian Institute of Public Health, Oslo, Norway. ${ }^{14}$ Department of Cardiology, University of Groningen, University Medical Center Groningen, Groningen, The Netherlands. ${ }^{15}$ HUNT Research Center, Department of Public Health and General Practice, Faculty of Medicine, Norwegian University of Science and Technology, Trondheim, Norway. ${ }^{16}$ THL-National Institute for Health and Welfare, Helsinki, Finland. ${ }^{17}$ Department of Laboratory Medicine, University of Groningen, University Medical Center Groningen, Groningen, The Netherlands. ${ }^{18}$ Department of Chronic Disease Prevention, National Institute for Health and Welfare, Helsinki, Finland. ${ }^{19}$ Department of Neurology, Central Hospital, Bolzano, Italy. ${ }^{20}$ Department of Neurology, University of Lübeck, Lübeck, Germany. ${ }^{21}$ Pirkanmaa hospital district and Finnish Diabetes Association, Tampere, Finland. ${ }^{22}$ University of Groningen, University Medical Center Groningen, LifeLines Cohort Study, Groningen, The Netherlands.

${ }^{23}$ Institute of Public Health and Clinical Nutrition, University of Eastern Finland, and Research Unit, Kuopio University Hospital, Kuopio, Finland.

Received: 26 January 2014 Accepted: 27 January 2014

Published: 1 February 2014

\section{References}

1. Swinburn BA, Sacks G, Hall KD, McPherson K, Finegood DT, Moodie ML, et al: The global obesity pandemic: shaped by global drivers and local environments. Lancet 2011, 378:804-814.

2. Berghofer A, Pischon T, Reinhold T, Apovian CM, Sharma AM, Willich SN: Obesity prevalence from a European perspective: a systematic review. BMC Public Health 2008, 8:200.

3. Rabin BA, Boehmer TK, Brownson RC: Cross-national comparison of environmental and policy correlates of obesity in Europe. Eur J Public Health 2007, 17:53-61.

4. Freedman DS: Obesity - United States, 1988-2008. MMWR Surveill Summ 2011, 60(Suppl):73-77.

5. Ogden CL, Carroll MD, Kit BK, Flegal KM: Prevalence of obesity in the United States, 2009-2010. NCHS Data Brief 2012, 1-8.

6. Finucane MM, Stevens GA, Cowan MJ, Danaei G, Lin JK, Paciorek CJ, et al: National, regional, and global trends in body-mass index since 1980: systematic analysis of health examination surveys and epidemiological studies with 960 country-years and 9.1 million participants. Lancet 2011 , 377:557-567.

7. Kelly T, Yang W, Chen CS, Reynolds K, He J: Global burden of obesity in 2005 and projections to 2030. Int J Obes (Lond) 2008, 32:1431-1437.
8. Mokdad AH, Ford ES, Bowman BA, Dietz WH, Vinicor F, Bales VS, et al: Prevalence of obesity, diabetes, and obesity-related health risk factors, 2001. JAMA 2003, 289:76-79.

9. Canoy D, Boekholdt SM, Wareham N, Luben R, Welch A, Bingham S, et al: Body fat distribution and risk of coronary heart disease in men and women in the european prospective investigation into cancer and nutrition in norfolk cohort: a population-based prospective study. Circulation 2007, 116:2933-2943.

10. Pischon T, Nothlings U, Boeing H: Obesity and cancer. Proc Nutr Soc 2008, 67:128-145.

11. Pischon T, Boeing $H$, Hoffmann K, Bergmann M, Schulze MB, Overvad K, et al: General and abdominal adiposity and risk of death in Europe. N Engl J Med 2008, 359:2105-2120.

12. Whitlock G, Lewington $S$, Sherliker $P$, Clarke R, Emberson J, Halsey J, et al: Body-mass index and cause-specific mortality in 900000 adults: collaborative analyses of 57 prospective studies. Lancet 2009, 373:1083-1096.

13. Bijlsma JW, Berenbaum F, Lafeber FP: Osteoarthritis: an update with relevance for clinical practice. Lancet 2011, 377:2115-2126.

14. Primeau V, Coderre L, Karelis AD, Brochu M, Lavoie ME, Messier V, et al: Characterizing the profile of obese patients who are metabolically healthy. Int J Obes (Lond) 2011, 35:971-981.

15. Grundy SM, Cleeman JI, Daniels SR, Donato KA, Eckel RH, Franklin BA, et al: Diagnosis and management of the metabolic syndrome: an american heart association/national heart, lung, and blood institute scientific statement. Circulation 2005, 112:2735-2752.

16. Eckel RH, Alberti KG, Grundy SM, Zimmet PZ: The metabolic syndrome. Lancet 2010, 375:181-183.

17. Stefan N, Kantartzis K, Machann J, Schick F, Thamer C, Rittig K, et al: Identification and characterization of metabolically benign obesity in humans. Arch Intern Med 2008, 168:1609-1616.

18. Wildman RP, Muntner P, Reynolds K, McGinn AP, Rajpathak S, Wylie-Rosett J, et al: The obese without cardiometabolic risk factor clustering and the normal weight with cardiometabolic risk factor clustering: prevalence and correlates of 2 phenotypes among the US population (NHANES 1999-2004). Arch Intern Med 2008, 168:1617-1624.

19. Velho S, Paccaud F, Waeber G, Vollenweider P, Marques-Vidal P: Metabolically healthy obesity: different prevalences using different criteria. Eur J Clin Nutr 2010, 64:1043-1051.

20. Kantartzis K, Machann J, Schick F, Rittig K, Machicao F, Fritsche A, et al: Effects of a lifestyle intervention in metabolically benign and malign obesity. Diabetologia 2011, 54:864-868.

21. Pajunen $P$, Kotronen A, Korpi-Hyovalti E, Keinanen-Kiukaanniemi S, Oksa H, Niskanen $L$, et al: Metabolically healthy and unhealthy obesity phenotypes in the general population: the FIN-D2D Survey. BMC Public Health 2011, 11:754.

22. Geetha L, Deepa M, Anjana RM, Mohan V: Prevalence and clinical profile of metabolic obesity and phenotypic obesity in Asian Indians. J Diabetes Sci Technol 2011, 5:439-446.

23. Denis GV, Obin MS: 'Metabolically healthy obesity': origins and implications. Mol Aspects Med 2013, 34:59-70.

24. Pataky Z, Bobbioni-Harsch E, Golay A: Open questions about metabolically normal obesity. Int J Obes (Lond) 2010, 34(Suppl 2):S18-S23.

25. Phillips CM, Dillon C, Harrington JM, McCarthy VJ, Kearney PM, Fitzgerald AP, et al: Defining metabolically healthy obesity: role of dietary and lifestyle factors. PLoS One 2013, 8:e76188.

26. Hamer M, Stamatakis E: Metabolically healthy obesity and risk of all-cause and cardiovascular disease mortality. J Clin Endocrinol Metab 2012, 97:2482-2488.

27. Hamer M, Stamatakis E: Low-dose physical activity attenuates cardiovascular disease mortality in men and women with clustered metabolic risk factors. Circ Cardiovasc Qual Outcomes 2012, 5:494-499.

28. Kuk $\lrcorner$, Ardern Cl: Are metabolically normal but obese individuals at lower risk for all-cause mortality? Diabetes Care 2009, 32:2297-2299.

29. Fortier I, Burton PR, Robson PJ, Ferretti V, Little J, L'Heureux F, et al: Quality, quantity and harmony: the DataSHaPER approach to integrating data across bioclinical studies. Int J Epidemiol 2010, 39:1383-1393.

30. Harris JR, Burton P, Knoppers BM, Lindpaintner K, Bledsoe M, Brookes AJ, et al: Toward a roadmap in global biobanking for health. Eur J Hum Genet 2012, 20:1105-1111.

31. Doiron D, Ferretti V, Burton P, Marcon Y, Gaye A, Wolffenbuttel BHR, et al: Data harmonization and federated analysis of population-based studies: the BioSHaRE project. Emerging Themes Epidemiology 2013, 10:12. 
32. Metspalu A: Estonian genome project-before the take-off and take-off. Bioinformatics 2002, 18(Suppl 2):S152.

33. Inouye M, Kettunen J, Soininen P, Silander K, Ripatti S, Kumpula LS, et al: Metabonomic, transcriptomic, and genomic variation of a population cohort. Mol Syst Biol 2010, 6:441.

34. Aromaa A, Koskinen S: Baseline results of the health 2000 health examination survey: health and functional capacity in Finland. Publications of the National Public Health Institute B12/2004. Edited by Aromaa A, Koskinen S. Helsinki: National Public Health Institute; 2004:1-148.

35. Wichmann HE, Gieger C, Illig T: KORA-gen-resource for population genetics, controls and a broad spectrum of disease phenotypes. Gesundheitswesen 2005, 67(Suppl 1):S26-S30.

36. Pattaro C, Marroni F, Riegler A, Mascalzoni D, Pichler I, Volpato CB, et al: The genetic study of three population microisolates in South Tyrol (MICROS): study design and epidemiological perspectives. BMC Med Genet 2007, 8:29.

37. Stolk RP, Rosmalen JG, Postma DS, de Boer RA, Navis G, Slaets JP, et al: Universal risk factors for multifactorial diseases: lifeLines: a threegeneration population-based study. Eur J Epidemiol 2008, 23:67-74.

38. Pinto-Sietsma SJ, Janssen WM, Hillege HL, Navis G, de ZD, de Jong PE: Urinary albumin excretion is associated with renal functional abnormalities in a nondiabetic population. J Am Soc Nephrol 2000 11:1882-1888

39. Krokstad S, Langhammer A, Hveem K, Holmen T, Midthjell K, Stene T, et al: Cohort profile: the HUNT study, norway. Int J Epidemiol 2013, 42:968-977.

40. Power C, Elliott J: Cohort profile: 1958 British birth cohort (National Child Development Study). Int J Epidemiol 1958, 2006(35):34-41.

41. World Health Organization (WHO): Obesity: preventing and managing the global epidemic. Report of a WHO consultation. World Health Organ Tech Rep Ser 2000, 894:-253.

42. Expert Panel on Detection Evaluation, and Treatment of High Blood Cholesterol in Adults: Executive summary of the third report of the national cholesterol education program (NCEP) expert panel on detection, evaluation, and treatment of high blood cholesterol in adults (adult treatment panel III). JAMA 2001, 285:2486-2497.

43. Sidhu D, Naugler C: Fasting time and lipid levels in a community-based population: a cross-sectional study. Arch Intern Med 2012, 172:1707-1710

44. Sundquist J, Johansson SE, Sundquist K: Levelling off of prevalence of obesity in the adult population of Sweden between 2000/01 and 2004/ 05. BMC Public Health 2010, 10:119.

45. Lissner L, Sohlstrom A, Sundblom E, Sjoberg A: Trends in overweight and obesity in Swedish schoolchildren 1999-2005: has the epidemic reached a plateau? Obes Rev 2010, 11:553-559.

46. Micciolo R, Di Francisco V, Fantin F, Canal L, Harris TB, Bosello O, et al: Prevalence of overweight and obesity in Italy (2001-2008): is there a rising obesity epidemic? Ann Epidemiol 2010, 20:258-264.

47. Rokholm B, Baker $\mathrm{JL}$, Sorensen TI: The levelling off of the obesity epidemic since the year 1999-a review of evidence and perspectives. Obes Rev 2010, 11:835-846.

48. Grundy SM: Metabolic syndrome pandemic. Arterioscler Thromb Vasc Biol 2008, 28:629-636.

49. Onat A: Metabolic syndrome: nature, therapeutic solutions and options. Expert Opin Pharmacother 2011, 12:1887-1900.

50. Onat A, Ceyhan K, Basar O, Erer B, Toprak S, Sansoy V: Metabolic syndrome: major impact on coronary risk in a population with low cholesterol levels-a prospective and cross-sectional evaluation. Atherosclerosis 2002, 165:285-292.

51. Nichols M, Townsend N, Scarborough P, Rayner M: Cardiovascular disease in Europe: epidemiological update. Eur Heart J 2013, 34:3028-3034.

52. Cornier MA, Dabelea D, Hernandez TL, Lindstrom RC, Steig AJ, Stob NR, et al: The metabolic syndrome. Endocr Rev 2008, 29:777-822.

53. Karelis AD, Messier V, Brochu M, Rabasa-Lhoret R: Metabolically healthy but obese women: effect of an energy-restricted diet. Diabetologia 2008 51:1752-1754

54. Criqui MH: Response bias and risk ratios in epidemiologic studies. Am J Epidemiol 1979, 109:394-399.

55. Heath GW, Parra DC, Sarmiento OL, Andersen LB, Owen N, Goenka S, et al: Evidence-based intervention in physical activity: lessons from around the world. Lancet 2012, 380:272-281.

56. Gordon T, Kannel WB, Dawber TR, McGee D: Changes associated with quitting cigarette smoking: the Framingham study. Am Heart J 1975, 90:322-328.
57. Cena H, Fonte ML, Turconi G: Relationship between smoking and metabolic syndrome. Nutr Rev 2011, 69:745-753.

58. Williamson DF, Madans J, Anda RF, Kleinman JC, Giovino GA, Byers T: Smoking cessation and severity of weight gain in a national cohort N Engl J Med 1991, 324:739-745.

59. Chiolero A, Faeh D, Paccaud F, Cornuz J: Consequences of smoking for body weight, body fat distribution, and insulin resistance. Am J Clin Nutr 2008, 87:801-809.

60. Sun K, Liu J, Ning G: Active smoking and risk of metabolic syndrome: a meta-analysis of prospective studies. PLoS One 2012, 7:e47791.

doi:10.1186/1472-6823-14-9

Cite this article as: van Vliet-Ostaptchouk et al.: The prevalence of metabolic syndrome and metabolically healthy obesity in Europe: a collaborative analysis of ten large cohort studies. BMC Endocrine Disorders 2014 14:9.

\section{Submit your next manuscript to BioMed Central and take full advantage of:}

- Convenient online submission

- Thorough peer review

- No space constraints or color figure charges

- Immediate publication on acceptance

- Inclusion in PubMed, CAS, Scopus and Google Scholar

- Research which is freely available for redistribution 